\title{
Aetiology of Chronic Pancreatic Fibrosis with Calcification Seen in Uganda
}

\author{
A. G. SHAPER,* M.B., CH.B., M.R.C.P., D.T.M.\&H.
}

Brit. med. F., 1964, 1, 1607-1609

Chronic pancreatic fibrosis with calcification is a well-recognized clinical condition in Uganda (Shaper, 1960, 1961), and the present communication reviews some of the features of this disorder in an attempt to assess possible aetiological factors. Since the first clinical diagnosis of this condition was made at Mulago Hospital, Kampala, in 1958 the number of cases recorded has steadily increased; in addition, exocrine pancreatic failure has been shown to be present in some African diabetic subjects in the absence of radiological evidence of calcification (Banwell et al., 1963). The disorder has also been recognized as fairly common in Nigeria (Kinnear, 1963) and in the Congo (Bourgoignie et al., 1962), where it is present in a significant proportion of diabetic subjects as well as in non-diabetics. The subjects discussed in this paper all presented prior to April 1962 and all had pancreatic calcification.

\section{Findings}

The manner of presentation of the 36 subjects with pancreatic calcification is shown in Table I. Two of those in whom the condition was found incidentally at necropsy were diabetic, two of those presenting with a pancreatitis syndrome became diabetic at a later date, and one subject with a malabsorption syndrome eventually developed diabetes. The overall incidence of diabetes mellitus in this group is $61 \%$.

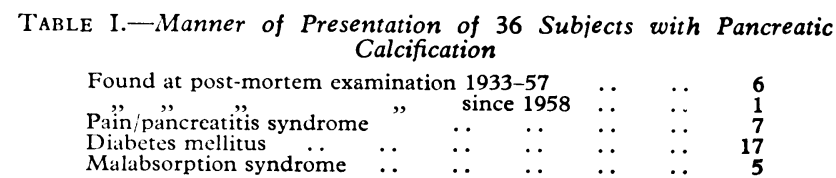

$\cdots$

All patients attending the diabetic clinic at Mulago Hospital undergo a radiological examination of the upper abdomen, and over the past three years (1959-62) pancreatic calcification has been observed in $8.3 \%$ of the males and $6.5 \%$ of the females, an overall incidence of $7.6 \%$ of those attending the clinic. Of 124 diabetics under the age of $45,12.9 \%$ manifested pancreatic calcification ; of 125 diabetics over the age of 45 , only $2.4 \%$ showed calcification. This suggests that the aetiological factors are active in the earlier decades of life. The average age at death in 18 subjects with calcification was 37 years (range 2150 years), and this may account for a low incidence in the older diabetics.

There were 28 males and 8 females, a male: female ratio of 3.5 to 1 . While this is the same as the male: female medical admission ratio of 3.4 to 1 (Shaper and Shaper, 1958), it may well be that comparison should be made with the overall hospital attendance pattern of 1.3 males to 1 female. If this assumption is reasonable it would suggest that the condition is several times more common in males than in females. The majority of subjects were of the Baganda tribe indigenous to the Kampala region, and the tribal distribution followed fairly closely the tribal distribution in Buganda according to the 1959 Census.

* Senior Lecturer in Medicine, Makerere University College Medical School, Kampala, Uganda.
Assessment of the social and economic class of these subjects proved extremely difficult, and was eventually made in a rather arbitrary fashion, indicating that 31 of the 36 patients were from a peasant-cultivator background, four were in positions of very minor responsibility, and one was a professional man.

It proved almost impossible to determine with any accuracy the history of childhood or adolescent nutritional patterns. While a history of the customary diet was obtained in most subjects, it reflects only the intake prior to hospitalization, and this may have been considerably modified by the illness itself and by the associated lack of earning capacity. The final assessment has been fairly crude and is based on a knowledge of social class, occupation, earning capacity, and the dietary history: good 1, fair 8, poor 24, and not known 3.

These gradings must be interpreted in local terms, and a good or fair diet will still be one rich in carbohydrate and low in protein and fats. A fair diet, for example, includes " meat once a week and fish or milk occasionally." The nutrition during childhood will have depended not only on the earning capacity of the parents but also on their knowledge of nutritional needs as opposed to traditional dietary patterns. It can be assumed that the parents of those who are adults in this study had little or no knowledge of nutritional requirements. With these factors in mind one can almost certainly move all these gradings much further down the nutritional scale.

Information about drinking patterns or alcoholism in Buganda is not readily available, and a definition of alcoholism in this setting will not be attempted. There is a great variation from group to group on what is regarded as moderate or heavy drinking, and in some subjects several bottles of banana-wine daily from adolescence would be regarded as quite a moderate intake. Subjects were on the whole eager to emphasize their present abstemious habits rather than to dwell on their more extravagant past, and the inquiries about alcohol have been repeated at frequent intervals in an attempt to elicit something like the truth. Many who gave a history of heavy drinking at some time in their lives claimed to have stopped or reduces. their drinking once the illness started, either because they thought alcohol had caused their illness or because it aggravated their symptoms. None had ever been admitted to hospital for delirium tremens, acute gastritis, or alcoholism, and none had be' $\mathrm{n}$ involved in any major accidents.

As Muslims are forbidden to take alcohol and are in theory abstainers, the pattern of religious affiliation in the pancreatic subjects was compared with the pattern of religion in Buganda (Uganda Census, 1959) and no differences were noted. Thr breakdown by religion of pancreatic subjects with diabetes mellitus was then compared with the breakdown for new diabetic admissions for 1959 and 1960, and again no significant differences were noted.

Nine subjects were definitely heavy drinkers at one time or another and a further seven were probably heavy drinkers (Table II), this latter assessment being based on their own variable histories and on reports obtained from friends and relatives concerning their personal habits. The group of abstainers includes two schoolboys, one of whom lived alont with his father who was a chronic alcoholic, and the group 
with inadequate information includes four women and two males. The two males might possibly be drinkers, as one gave a history of repeated haematemeses in the absence of cirrhosis, suggesting alcoholic gastritis, and the other was a waiter in a roadside eating-house. Further attempts are being made in all cases to re-explore the histories even in those already dead. At present, however, it seems that alcohol may be a factor of some significance in about $50 \%$ of the cases.

$$
\begin{aligned}
& \text { TABLE II.-Alcoholic Consumption in } 30 \\
& \text { Calcification }
\end{aligned}
$$

In 21 subjects a normal gall-bladder and bile-duct system was demonstrated at operation or necropsy or on cholecystography. In 14 subjects normal gall-bladder function was a clinical assumption based on the absence of any history suggesting cholecystitis or cholelithiasis. In one subject several small pigment stones were found at necropsy. Cholelithiasis and cholecystitis are extremely uncommon disorders in patients attending Mulago Hospital (Shaper and Patel, 1964).

\section{Clinical Features}

Pain was present in moderate to severe degree in 18 subjects and was mild, doubtful, or absent in 18 others. There was no apparent difference in alcohol intake between these two groups.

The age at onset of pain ranged from 10 to 53 years, and diabetes developed in 10 subjects with pain after an average period of three years at a mean age of 37 years (Table III). In the pain-free group 11 subjects manifested diabetes at an average age of 30 years. In both groups calcification was diagnosed

\begin{tabular}{|c|c|c|c|}
\hline & & $\begin{array}{l}\text { Subjects with } \\
\text { Pain (18) }\end{array}$ & $\begin{array}{c}\text { Subjects without } \\
\text { Pain (18) }\end{array}$ \\
\hline $\begin{array}{l}\text { Pain } \quad . \\
\text { Diabetes .. } \\
\text { Calcification } \\
\text { Death .. }\end{array}$ & $\begin{array}{l}\cdots \\
\cdots \\
\cdots\end{array}$ & $\begin{array}{l}30 \text { years } \\
37 \% \text { (10) } \\
33 \% \text { " } \\
37 \%\end{array}$ & $\begin{array}{l}30 \text { years }(11) \\
33 \% \quad(10) \\
37 \% \quad \text { " }\end{array}$ \\
\hline
\end{tabular}
at an average age of 33 years (range 12-54 years), and death occurred at an average age of 37 years (range $21-50$ years).

TABle III.-Average Age at Diagnosis of Various Clinical Features in Subjects with Pancreatic Calcification (Number of Subjects Con cerned Indicated in Parentheses)

It is highly unlikely that these two arbitrarily separated groups represent different disorders. If anything, these observations suggest that pain is not an essential feature and that this disorder can progress to an advanced stage without the painful episodes which usually mark the onset and recurrence of relapsing pancreatitis.

\section{Discussion}

While little is known about the fundamental mechanisms of pancreatitis, it is reasonable to state that at a practical level the direct or indirect cause of pancreatitis in many patients in Western countries is often known. Alcoholism and cholelithiasis and choledocholithiasis are definite major causes of acute and recurrent pancreatitis, and the main features of gall-stones and alcoholic pancreatitis are here briefly described, so that these descriptions may later be used for comparison with the series from Kampala.

Pancreatitis associated with gall-stones is usually marked by acute episodes and numerous recurrences of clearly defined attacks. Diabetes, steatorrhoea, and pancreatic calcification are infrequent sequelae, for parenchymal replacement is not as extensive as in the alcoholic form.
Alcoholic pancreatitis has features quite separate from those of gall-stone pancreatitis and has an almost entirely different natural history. It is characteristically a disease of younger

\begin{tabular}{|c|c|c|c|}
\hline & & Gall-stone Pancreatitis & Alcoholic Pancreatitis \\
\hline $\begin{array}{l}\text { Average age (years) } \\
\text { Sex ratio }(M: F)\end{array}$ & $\ldots$ & $\begin{array}{l}53 \\
1 \text { to } 2 \cdot 7\end{array}$ & $\begin{array}{c}36 \\
2 \cdot 5 \text { to } 1\end{array}$ \\
\hline $\begin{array}{ll}\text { Calcification } & \ldots \\
\text { Diabetes mellitus } \\
\text { Steatorrhoea } \\
\text { Total deaths } \quad \ldots\end{array}$ & $\begin{array}{l}\cdots \\
\cdots \\
\cdots\end{array}$ & $\begin{array}{l}1.8 \% \\
0.6 \% \\
0.6 \% \\
8 \%\end{array}$ & $\begin{array}{l}53 \% \\
22 \% \\
21 \% \\
29 \%\end{array}$ \\
\hline
\end{tabular}
people, presenting at an average age of 36 years as compared with an average of over 50 years in gall-stone pancreatitis (Table IV). More than twice as many males as females are

TABLE IV.-Clinical Features of Pancreatitis Associated with Gall-stones and Alcoholism (From Howard, 1960)

affected by alcoholic pancreatitis, while in gall-stone pancreatitis females predominate. Most of the patients with alcoholic pancreatitis go on to develop pancreatic calcification, diabetes, and steatorrhoea. In these cases, along with pancreatic disease go the other manifestations of alcoholism: gastritis, delirium tremens, cirrhosis, tuberculosis, and peptic ulcer. Alcoholic pancreatitis occurs chiefly in persons who drink heavily .and repeatedly, often habitually, and there is no evidence that pancreatitis results from the occasional modest intake of alcohol.

Although pancreatic calcification evidently can occur as a result of relapsing pancreatitis of any type, it is, according to many authorities, characteristically a late sequel in the course of chronic alcoholism and alcoholic pancreatitis. In a personal study of 62 cases in Philadelphia, Howard (1960) came to regard pancreatic calcification as almost (but not quite) pathognomonic of chronic alcoholism, and at least $80 \%$ of his patients with this condition were alcoholics.

Included in Howard's series of 62 subjects with pancreatic calcification were 32 indigent patients from a single charity hospital, and in Tables V and VI this indigent group is compared with the Kampala series.

Table $\mathrm{V}$ compares the average age at onset or diagnosis of the various stages in this disorder; while there are interesting differences the two groups obviously have much in common,

\begin{tabular}{|c|c|c|}
\hline & Kampala (36 Cases) & Philadelphia (32 Cases) \\
\hline $\begin{array}{l}\text { Average age at onset/ } \\
\text { diagnosis of : }\end{array}$ & & \\
\hline $\begin{array}{lll}\text { Pain } & \ldots & \ldots \\
\text { Calcification } & \ldots & \ldots \\
\text { Diabetes } . . & \ldots & \ldots \\
\text { Death } \quad . . & \ldots & \ldots\end{array}$ & $\begin{array}{l}30 \text { years } \\
33 \% \\
33 " \\
37 "\end{array}$ & $\begin{array}{l}33 \text { years } \\
39 ", \\
40 ", \\
48 ",\end{array}$ \\
\hline
\end{tabular}
far more so than with any other aetiological group in pancreatitis.

TABle V.-Comparison of Age at Onset/Diagnosis of Clinical Features in Subjects with Pancreatic Calcification in Kampala and in Philadelphia, U.S.A. (Howard, 1960)

In Table VI the incidence of certain features in these two groups is compared. It would appear that, while alcoholism is certainly a far less definite factor in the Kampala series and pain less frequent, the incidence of diabetes mellitus, steatorrhoea, and death is much higher.

Before drawing any conclusions about the role of alcohol, the possible role of protein malnutrition in the aetiology of this condition must be mentioned. Zuidema (1959) has reported

TABLE VI.-Comparative Incidence of Certain Features in Subjects with TABLE VI.-Comparative Incidence of Certain Features in Subied

\begin{tabular}{lll|c|c}
\hline & & Kampala (36 Cases) & Philadelphia (32 Cases) \\
\hline Alcoholism & $\ldots$ & $\ldots$ & $\pm 53 \%$ & $100 \%$ \\
Pain & $\ldots$ & $50 \%$ & $90 \%$ \\
Diabetes mellitus & $\ldots$ & $61 \%$ & $34 \%$ \\
Steatorrhoea &. & $\ldots$ & $76 \%$ & $38 \%$ \\
Death.. &. &.. & $50 \%$ & $25 \%$
\end{tabular}


18 Indonesian subjects aged 15 to 30 years with pancreatic calcification and diabetes. All were living on diets very low in protein and did not drink alcohol at all, and he thought the condition could well be due to protein malnutrition. There are striking changes in the pancreas in protein-calorie malnutrition in infants, and protein deficiency has been shown clinically and experimentally to diminish exocrine secretions and to produce histological changes in the pancreas. Ethionine, an antimetabolite of the essential amino-acid methionine, has been used experimentally to interfere with protein metabolism and to produce pancreatic lesions varying from mild atrophy to severe haemorrhagic necrosis. While there seems to be a great deal of experimental evidence to indicate that protein malnutrition can affect the pancreas adversely, it must be remembered that, in those children with kwashiorkor who recover, the recovery appears to be complete, and there has been no confirmed report of diabetes mellitus or pancreatic disease following kwashiorkor.

In conclusion, the pattern of pancreatitis seen in Kampala bears a significant resemblance to alcoholic pancreatitis. While many of its manifestations are less acute, overall it seems to be an even more severe process. Diabetes and malabsorption are very common, and the effects of malabsorption are far more pronounced than in the subjects referred to from Philadelphia (Howard, 1960). The whole process would appear to start at a somewhat earlier age and to run its course even more rapidly.

Little is known about the mechanism by which alcohol causes pancreatitis, and the current theory suggests that a high oral alcohol intake produces an increased volume of pancreatic juice via the secretin mechanism, against an obstruction produced by alcoholic duodenitis. It seems that alcohol played a part of some significance in about half of our cases, but it did so against a background of a low-protein high-carbohydrate diet. In those subjects seen in Kampala in whom alcohol was not a definite factor, was this due to an inadequate history, was this a protein malnutrition syndrome, or were there other factors which may have initiated lesions in a pancreas rendered vulnerable to injury by a low protein intake? There is as yet no firm evidence that protein malnutrition per se will produce irreversible pancreatic disease in adults.

It would seem that the condition of chronic pancreatic fibrosis with calcification seen in Uganda is not simply a problem of alcoholic pancreatitis, and it is almost certainly not a pure problem of protein malnutrition. Further studies are in progress to discover the incidence of this problem in the community and to assess the role of pancreatic injury in childhood in relation to chronic pancreatic diseases in later life.

\section{Summary}

The main clinical features present in 36 African subjects with pancreatic calcification are described and the possible aetiological factors discussed. The natural history of this disorder resembles that of alcoholic pancreatitis seen in other countries, and, while episodic heavy drinking (but not necessarily alcoholism) was noted in about half the subjects, it is emphasized that it took place against a background of low-protein high-carbohydrate nutrition. It is suggested that this tropical syndrome and alcoholic pancreatitis may have a similar pathogenesis, and that, in a pancreas rendered susceptible to injury by nutritional imbalance, alcohol and/or other factors may initiate progressive and irreversible pancreatic damage. It must be emphasized that this is not regarded as alcoholic pancreatitis, nor is it thought that the problem is purely one of protein malnutrition.

\section{REFERENCES}

Banwell, J. G., Campbell, J., Blackman, V., Hutt, M. S. R., and Leonard, P. (1963). E. Afr. med. F., 40, 277 .

Bourgoignie, J., Sonnet, J., and Dechef, G. (1962). Ann. Soc. belge Méd. trop., 42, 261.

Howard, J. M. (1960). In Surgical Diseases of the Pancreas, edited by J. M. Howard and G. L. Jordan. Pitman, London.

Kinnear, T. W. G. (1963). E. Afr. med. F., 40, 288.

Shaper, A. G. (1960). Lancet, 1, 1223.

(1961). Proceedings of 4 th Congress International Diabetes Federation, Geneva, 1, 119 .

and Patel, K. M. (1964). E. Afr. med. F. In press.

- and Shaper, L. (1958). Ibid., 35, 648.

Uganda Census (1959). East African Statistical Department, Entebbe.

Zuidema, P. J. (1959). Trop. geogr. Med., 11, 70.

\title{
Treatment of Typhoid Carriers with Ampicillin
}

\author{
A. B. CHRISTIE,* M.A., M.D., D.P.H., D.C.H.
}

Brit. med. F., 1964, 1, 1609-1611

The effect of chloramphenicol on the clinical course of typhoid fever has been one of the more dramatic triumphs of the antibiotic era: a long, low, muttering fever is converted into a short, sharp, febrile illness. Unfortunately its use in the acute stage does not guarantee that the convalescent patient is free from infection, and its effect in the established carrier has been very disappointing. Massive penicillin therapy, with or without the addition of sulphonamides or probenecid, has proved equally ineffective, and cholecystectomy has remained, in this age of antibiotics, the surest method of ending the carrier state. The present report deals with the treatment of eight typhoid carriers with ampicillin.

\section{Eight Carriers}

Seven of the eight carriers were mental-hospital patients, and had been in hospital for between 7 and 47 years: all were females. Six of them had been known typhoid carriers for between 7 and 27 years ; all six had had previous treatment for their carrier state, most of them several times, with penicillin and sulphonamides, streptomycin, furazolidone ("furoxone"), and chloramphenicol, with or without corticosteroids. The treatment was thorough but without effect. The seventh mental-hospital patient had been in hospital 36 years: she has been a known carrier only since 1962, though there is an unconfirmed record of her having been a carrier for 11 years before that ; there is no record of previous treatment. The eighth carrier worked in a school canteen: at the time of her discovery her hushand and son-in-law were suffering from typhoid fever, and one school child had caught the infection: she had no history of an illness like typhoid fever and the length of her carrier state is unknown.

Preliminary Surveillance.-The seven mental-hospital patients were put on bacterial surveillance for five months before treat-

\footnotetext{
* Physician-Superintendent, Fazakerley Hospital, Liverpool.
} 